\title{
Leadership From A Global Perspective
}

Almerinda Forte, St. John's University, USA

\begin{abstract}
Leaders are promoters of change and challengers of the norm by encouraging creativity and risk taking. Leaders concentrate on goals, objectives, mission, and vision. They concern themselves with doing the ethical or right thing. Corporations have grown into multinational firms due to trust, loyalty and support of the components they serve. Businesses are more global today. These firms are challenged with the task of maintaining trust and balancing the numerous, often competing needs of their stakeholders. Needs include greater profits, lower price for consumers, higher wages for employees, less waste and pollution, and growing demands for ethical and moral behavior. Technology has made many actions crystal clear as to what standards should be followed. However, today managers need to know how to be global managers. This is a must in order for large corporations to effectively function and succeed in the global market. What does a global manager need to know to lead responsibly? This paper addresses corporate sustainability leadership within the global compact.
\end{abstract}

Keywords: Corporate Sustainability Leadership; Global Compact; Corporate Social Responsibility

\section{TAKER, MATCHER, OR GIVER IN A CORPORATE SETTING}

orporate leaders hold the future success of the company in their hands. They influence others to achieve group or organizational goals in a highly technological and globalized environment. Leaders deal with a wide variety of people from numerous cultures and customs. They engage in making high quality decisions which impact the success or failure of a corporation. What does a global leader need to be and know in order to lead a growing, responsible and successful company? Let us first examine what a global leader needs to be. I believe that Adam Grant's book titled Give and Take can help facilitate the process of finding a leader who has the potential to create a successful, prosperous and growing company in this global economy. His research deals with identifying whether one is dealing with a taker, matcher, or giver in a corporate setting. This knowledge can help provide a futuristic snapshot of the potential success or demise a company might face. The success or failure of a corporation impacts not only the company itself, but also company stakeholders.

Adam Grant describes takers as dominant and controlling toward subordinates. In contrast, his research shows takers to be submissive and deferential when dealing with superiors. Influential people tend to form glowing first impressions of takers because takers charm and flatter them. Takers become persuasive fakers when dealing with influential people. Research indicates that as people achieve more power, they feel grand and in control. They are less inhibited and feel free to express and expose their natural tendencies. Takers feel entitled to pursue selfserving goals. They claim as much value for themselves as they can. Over time, takers treat their peers and subordinates poorly. In doing so, they compromise both their relationships and their reputations. Research indicates that people who have been burned by takers will retaliate by sharing their negative impressions, thus smearing reputations. Such gossip is a widespread form of a low-cost punishment. As a result, takers regularly cut existing ties and burn bridges with potential ties.

According to Grant, most people are matchers. Matchers' core values accentuate fairness, equality, and reciprocity. They are devoted to a quid pro quo system whenever they help others. This limits their networking. Matchers give with the expectation of receiving, directing their efforts only toward people they think can help them. Thus, they limit their networking. Alternatively, givers expect nothing in return. They try to make connections and maintain relationships that afford them the opportunity to do things for others regardless of reciprocity. 
Kenneth Lay from Enron is an example of a taker. His success sprang from building a network of powerful contacts and leveraging them for his own benefit. It was known that Lay would attend a meeting only when someone he considered important was attending. Making a good impression was an obsession of his. Lay worried little about how his subordinates perceived him. He exploited his own employees by having them compromise their integrity in order to create a façade that would impress and deceive Wall Street analysts. The Bush family distanced themselves from Lay when his true colors were revealed.

Usually, takers are self-absorbed. They primarily use first person singular pronouns such as "I," "me," "mine," "me," and "myself." Takers who are part of top management earn far more money than other senior executives in their organizations. They feel entitled to substantial pay discrepancies because takers perceive themselves as superior to everyone else. Kenneth Lay felt so superior that his sandwiches were served on a silver platter and fine china. Lay took excessive loans from his company, and its annual reports featured a full page photo of him. These examples are indicative of how Lay overvalued himself.

Kenneth Lay impressed George W. Bush so much that when Bush was running for governor, he asked Lay to chair one of his finance campaigns. Lay declined the offer because he thought Bush had little chance of winning. He told George W. Bush that he had accepted an appointment to serve on a business council for Ann Richards, the Democratic candidate. However, Lay did donate $\$ 12,500$ to George W. Bush's campaign. Toward the end of the campaign, it became obvious that Bush would win. At that point, Lay donated an additional $\$ 12,000$ to Bush's campaign. It turned out that Lay donated more to Bush's campaign than Richards'. His choice to give only when strategically beneficial backfired on him. It created an incredible gap in the relationship. George W. Bush never invited Lay to stay at the White House. Lay had previously been invited by George W. Bush's father. He functioned on a quid pro quo basis, helping Bush so that Bush would support his causes. Lay suggested that he would reciprocate if Bush would advance his agenda.

Adam Grant notes that reciprocity is a potent norm. One pitfall is that people on the receiving end feel they are being used. Favors with strings attached can be off-putting. They feel more like transactions than relationships. The person receiving can and will question motives. Do you really care about helping me? Are you trying to create a quid pro quo situation so that you can cash in on a favor in return?

Grant examines the challenge in networking. A person involved in networking tries to guess the motivation and purpose of a new contact, since takers can pose as givers when there is an impending return. Brian Uzzi (2005), a Northwestern University management professor, states that networking holds three major advantages. Networking provides private information, diverse skills, and power. He further notes that when people build a robust network, they gain priceless access to knowledge, expertise, and influence. According to Adam Grant's book, massive research finds that people with solid networks achieve higher performance ratings, get promoted faster, and earn more money. Grant's book addresses the fact that networking usually carries a negative connotation. When people meet persons who express an interest in connecting, they often wonder whether the persons are interested in a mutually beneficial relationship or if they simply want something from them. Takers take a Machiavellian approach. They perceive networking as a self-serving activity, connecting only in order to pursue their own interests. Grant states that givers and matchers often perceive networking as an attractive way to connect with new people and ideas. They exchange help and advice. Givers produce great and lasting amounts of networks in ways not readily apparent. LinkedIn founder, Reid Hoffman, was quoted in Grant's book. He states, "If you set out to help others," you will rapidly reinforce your own universe of possibilities. Reid Hoffman is a giver (Grant, 2013, p. $31)$.

Matchers, according to Grant, usually build smaller networks than givers or takers. Takers often expand their networks to compensate for the bridges burned from past relationships. Matchers function from the notion that they will do something for you if you do something for them. This notion results in a much narrower networking scope.

Grant identifies Adam Rifkin as a giver as well. He had more LinkedIn connections to the 640 influential people on Fortune's lists than any other person in the world. In Grant's book, Rifkin states that he would like to see more people helping other people. He decided to shut down Renkoo and became a full-time giver. He offered a 
wide range of guidance to start-ups and worked to link engineers and entrepreneurs with business people in huge companies. In 2005, Rifkin and Joyce Park established 106 miles, a professional network that possesses a social mission of educating entrepreneurial engineers through dialogue. Rifkin was an admirer of Blogger, a young blog publishing service which had run out of funds. Rifkin provided Blogger's founder with a contract to do work for his own first start-up. He wanted Blogger to survive, and his contract kept Blogger afloat. Blogger's founder thus had the opportunity to cofound a company called Twitter. Rifkin gives more than five times as much as he gets from LinkedIn. Takers and matchers give when they network, but they give strategically. Takers and matchers focus on who can help them in the future. This determines what, where and how they give. Robert Cialdini is quoted in Grant's book as saying, "People can capitalize on this norm of reciprocity by giving what they want to receive." Takers and matchers proactively offer favors to people they want and need help from in the future (Grant, 2013, p. 43).

Adam Grant also discusses dormant ties in his book. He found that these ties provided more information than current associates. Levin and his colleagues state that reconnecting with dormant associates is unlike initiating a relationship from square one (Grant, 2013, p. 50). Levin notes that people who reconnect still share feelings of trust. Levin finds that mutual trust built years ago facilitates conversation. Revitalizing a dormant tie requires a shorter conversation because of the previous foundation. Adam Grant perceives dormant ties as abandoned value in networking. Givers hold an edge over takers and matchers in reopening this value.

Takers revitalizing dormant ties face a great challenge. Dormant ties that are also takers will be apprehensive and self-protective. Therefore, they withhold important information. Matchers who are dormant ties might be inclined to punch takers. Givers who are dormant ties are unwilling to help takers. When takers' selfserving actions caused a tie to become dormant in the first place, attempts at revitalizing the connection may be futile.

Matchers have an easier time reconnecting than takers. Even so, they feel uncomfortable reconnecting because of their devotion to reciprocity. Matchers feel they owe a favor back to whomever they asked a favor from. Matchers do not build a deep pool of trust because they have been involved in a transactional exchange rather than a meaningful association.

Givers, on the other hand, have a record of easily sharing their knowledge, teaching their skills, and aiding in finding jobs for others without anguishing over what is in it for them. Dormant ties are happy to help givers when they get back in touch with them. They are grateful for the givers' previous help. The dormant tie also knows that the help came with no strings attached. When dormant ties are contacted, they are more than willing to share their knowledge and advice in order to help the giver.

Adam Rifkin believes we should view networks as a medium for creating value for everyone, not just ourselves. Rifkin follows a five minute rule. He believes everyone should be willing to do something that takes five minutes or less for anyone. Givers provide rich networking. They create norms that enhance value rather than claiming or trading value, therefore benefiting all parties involved.

Adam Grant discusses George Meyers, a well- known writer for The Simpsons. Meyers is a giver, and is extremely successful in collaborative work. Grant investigated what made Meyers so successful with teams. He was regarded as a man with a code of honor, and a man who truly lives by his code. He also possesses an unnatural amount of integrity, according to colleague Carolyn Omine. Grant points out that Meyers was well aware that his success depended on others more so than people realize.

Liz Wiseman, a former Oracle executive, classified Meyers as a genius maker. In Grant's book, she contends that geniuses are usually takers who promote their own interests. They tend to drain intelligence, energy, and capability from others. Genius makers are givers who use their intelligence to extenuate the brilliance and capabilities of other people. Wiseman writes that "light bulbs go off over people's heads, ideas flow, and problems get solved." This was George Meyers, who himself is a highly creative person (Grant, 2013, p. 63).

Huckman and Pisano researched (2006) whether or not top surgeons got better with practice. They found that surgeons improved only at the hospitals where they primarily practiced. The study showed that surgeons do not 
get better with practice alone. Huckman and Pisano's investigation found that for every procedure surgeons performed at their primary hospitals, the risk of patient mortality dropped by one percent. The results showed that the risk of mortality stayed the same at other hospitals. The research concluded that surgeons were unable to take their performance with them. The surgeons were not improving their skills. Rather, they were becoming more accustomed to particular nurses and anesthesiologists. The surgeons learned and were aware of the strengths, weaknesses, habits, and styles of their teams. This in turn aided the surgeons in avoiding patient deaths. Huckman and Pisano did not find this to carry over to other hospitals. The researchers concluded that in order for patient mortality to be reduced, surgeons required relationships with specific surgical teams.

Boris Groysberg (2008) researched more than a thousand equity and fixed-income security analysts during a nine year period at seventy-eight dissimilar firms. The effectiveness of the analysts was ranked by the number of clients they had at investment management institutions. Groysberg (2008) examined their quality of earnings estimates, their knowledge of the industry, their written reports, service, stock selection, and accessibility and responsiveness. The study revealed that the top three analysts in each of the eighty industry sectors were ranked as stars.

The stars earned between \$2 million and \$5 million. Groysberg's (2008) study revealed that the stars' performance wasn't portable. When the star analysts transferred to different firms, their performance dropped. The results showed that their performance lagged for at least five years. The researcher found that the stars who transferred with their teams showed no decline in performance. Groysberg found that the star analysts who moved by themselves had a five percent chance of being ranked first. Star analysts who moved with teammates had a ten percent chance of being ranked first. The study found the same to be true of the stars who did not move at all. Groysberg (2008) and his fellow researchers found that analysts are more likely to maintain their star performance if they work with their high quality colleagues who are part of their team and department. The study revealed that this is so because the analysts rely on knowledgeable colleagues for information and new and innovative ideas. In conclusion, both the star investment analysts and the cardiac surgeons depended immensely on the collaborators who they knew and who knew them. Both parties possessed strong skills and were aware of each other's strengths.

Grant explains that takers tend to see themselves as superior, therefore they separate themselves from others. The perception is that if they become too dependent on others, they will eventually be outdone. Givers, according to Grant, reject this belief. Interdependence is not considered a weakness to givers. They view it as a source of strength. They view it as being a way to harness the skills of multiple people for a larger good. Meyers was noted in Grant's book as going out of his way to support his teammates. Grant describes givers as collaborators. Givers assume tasks that are in the best interest of the group, not just tasks which are in their own best interest. According to Grant, studies reveal that people who give their time and knowledge frequently to help teammates earn more raises and promotions. Studies revealed these results from a wide variety of industries, stemming from banks to manufacturing companies. This type of behavior is known as expedition behavior. George Meyer exhibited this behavior. According to Grant's book, Meyers always put the group's goals and the mission of the firm first. He also showed the same amount of concern for others as he did for himself.

Grant asserts that Meyers was also known for building goodwill. He volunteered for unpopular tasks and offered feedback on ideas. Meyers demonstrated his comedic gifts without making his colleagues feel insecure. According to Eugene Kim and Theresa Glomb (2010), exceptionally talented people make others jealous (Grant, 2013, p. 75), thus placing themselves at risk for being disliked, resented, ostracized, and undermined. Givers do not have a target on their backs. They are appreciated for their contribution to the group because they take on unwanted tasks. Meyers' code of honor consists of showing up, working hard, being kind, and taking the high road. He was able to reveal his skills without creating jealousy. His colleagues admired and trusted him. He motivated people. Edwin Hollander (1958) states that when people act generously in groups they earn idiosyncrasy credits, positive impressions that accumulate in the minds of group members (Grant, 2013, p. 76).

Grant explains that people think like matchers when they work in groups. They keep track of each member's contributions. When group members earn idiosyncrasy credits through giving, matchers will grant those members a pass to deviate from team norms or expectations. 
Colleagues will listen to givers and reward them for speaking up because they know the motivation is coming from a genuine desire to contribute. Collective Achievement is another element which needs to be examined closely according to Grant's book. Reid Hoffman, LinkedIn founder, states that people tend to overvalue their own contributions and undervalue those of others (Grant, 2013, p. 82). Professional relationships disintegrate when executives feel that their partners are not giving them the credit that is due to them or if they are not doing their fair share. A taker's motivation is to get more than he or she gives. Takers cautiously count every contribution made. According to Grant, studies indicate that when employees consider how much help they have received from their superiors before considering how much they have contributed to their superiors, their estimates of their superiors' contributions double, from under seventeen percent to over thirty-three percent (Grant, 2013, p. 84).

Harvard Business School Professor Amy Edmondson's research revealed that Meyers created a psychologically safe environment for his group. He helped them create, people learned, and innovation increased (Grant, 2013, p. 85). They knew Meyers cared about them. Givers like Meyers shift their frame of reference to the recipient's perspective. This is known as the perspective gap. Meyers was a leader who stepped outside of his own frame of reference. He was able to feel what the recipient would feel in a given situation. He empathized.

The maintenance of motivation proves itself vital in leading successfully. Bill Gates argued at the World Economic Forum that "there are two great forces of human nature, self-interest and caring for others. People are most successful when they are driven by a 'hybrid engine" (Grant, 2013, p. 157). Adam Grant describes givers as selfless. Successful givers, according to Grant, are otherish. They are about benefiting others. However, they also hold ambitious goals for advancing their own interests. Grant explains that being otherish means being willing to give more than you receive, while keeping your own goals in sight. According to Grant, you integrate them. Grant believes that when a person's concern for others is coupled with a strong dose of self-concern, a giver will not burn out and is positioned to thrive. Givers don't burn out because they devote an enormous amount of time and energy to giving. They burn out when their hard work and time has not helped people effectively. When givers know their work makes a difference, they become invigorated to contribute more. Burnout is reduced when the impact is evident. Carnegie Mellon and Vicki Helgeson (2000), psychologist, assert that when people give on a constant basis without concern for their own well-being, they are prone to poor mental and physical health. However, their research revealed that when people give in an otherish manner, they no longer experience health issues. Results indicated that people who maintain equilibrium between benefitting others and themselves achieve noteworthy increases in happiness and life satisfaction over a six month period (Grant, 2013, p. 170). Grant also recommends that time should be donated in chunks, not in small amounts. The people who donated chunks of time achieved gains in happiness over people who donated time in small amounts. Grant distinguishes them as chunklers and sprinklers.

Lyuborninsky and colleagues found that happiness increased when people performed five giving acts in a single day, rather than doing one per day. They believe that "spreading them over the course of a week might have diminished their salience and power or made them less distinguishable from participant's habitual kind behavior" (Grant, 2013, p. 171).

Research reveals that people who volunteer two hours a week experience increased happiness, satisfaction, and self-esteem a year later. Studies indicate that two hours a week is the midpoint where donating time and satisfaction is reached without becoming overwhelmed. Research found that five hours a week had diminishing returns when volunteering. Studies also showed that the volunteers were learning less and less with each additional hour. Any time donated after eleven hours a week showed no added new knowledge and skills (Grant, 2013, p. 174). Psychologists Netta Weinstein and Richard Ryan (2010) found that giving results in an energizing effect if the volunteer finds the activity enjoyable and meaningful. If the activity is perceived as a duty or obligation, the effect is negative. When giving is considered an enjoyable and meaningful activity, the giver earns an increased sense of autonomy, mastery, and connection to others. This in turn generates higher energy (Grant, 2013, p. 175).

Adam Grant points out that otherish givers recognize the importance of shielding their own well-being. If they start to experience burnout, they look for help. This provides them with the resources they need to maintain motivation and energy. More than three decades of research reveal that support from colleagues serves as a healthy remedy to burnout. Studies indicate that giving increases happiness and meaning. This in turn motivates people to 
work harder and earn more money. Elizabeth Dunn, Lara Aknin, and Michael Norton (2008), psychologists, found that spending money on yourself does not change your happiness. However, when people spent money on others, they reported increased happiness. Otherish giving allows persons to choose who they want to help. It uplifts their mood. Neuroscience has found that giving activates the reward and meaning centers of the brain. This sends pleasure and purpose signals making people feel good about helping others. Giving adds meaning to people's lives. Giving makes people feel valued and allows them to escape their own problems (Grant, 2013, p. 183). Roy Baumeister, Kathleen Voks, Jennifer Aaker, and Emily Garbinsky found from a national survey of Americans that meaningfulness is linked to being a giver more than a taker. Research reveals that happiness can motivate people to work harder, longer, smarter, and more effectively. Happy people set more challenging goals for themselves, think more quickly, are more flexible, and hold a broader view of dealing with problems. Studies show that happy people earn more money. They receive higher performance ratings. Happy people make better decisions and negotiate better deals. They also contribute more to their firms. The feeling that they are making a difference remains key.

In order for global managers to lead responsibly, they must be aware that different countries favor different motivating corporate social responsibilities and principles. Research such as Maignan and Relston (2002), Tinike Lamboody (2010), Antonio Tencati (2006), and Fiori, di Donato and Izzo (2007) just to name a few have found this to be true. Corporate social responsibility has a value-driven approach in the United States, whereas the U.K. and other European countries favor a performance-driven approach. European countries tend to emphasize traditional production and promotion-oriented programs. The U.K.'s CSR discusses sponsorships, health, and safety initiatives. CSR in the U.K. also deals with the arts and culture, environmental protection, education, safety, and quality of life. French, Dutch, and British firms focus on environmental protection. Research has found this to be the number one issue cited. CSR in France is connected to their productive activities. Studies revealed the Dutch firms focus on the protection of the environment, arts, and culture, and employee health and safety. Many countries, such as Poland, still need to implement CSR in their companies. According to Justyna Berniak-Wozny (2010), in order to do this, corruption and unethical behavior in the business circles of these countries must be rejected. Research has found that U.S. companies give primarily to their communities through philanthropic programs. United States firms tend to reach beyond basic production and promotion activities when dealing with CSR, according to studies' findings. U.S. companies mention quality of life and education. Businesses in the U.S. tend to zero in on issues that are not directly connected to their activities. U.S. firms pay attention to the arts, education, culture and quality of life when dealing with CSR issues. According to the numerous research findings, culture plays a definitive role in CSR. Countries which hold social democratic traditions customarily have CSR policies. Richard Welford's (2004) research found links between culture and CSR policies. CSR policies were predominant in countries with social democratic traditions. According to Welford, the more developed a country, the greater the probability they will engage in CSR policies. Examples of this include Canada, Germany, the U.S. and the U.K. The U.K. and Germany are the leaders of CSR in Europe according to Welford's findings. In order to promote a socially responsible image, countries favor different CSR initiatives and emphasize their dedication to different stakeholder issues. Companies and investors who have not realized that medium to long term returns are just as important as short term returns will realize with time that CSR benefits both image and livelihood. It is imperative that corporate leaders entering a new country acquaint themselves with that country's dedication to CSR and the CSR policies they emphasize. This familiarity will allow them to better plan, improve, and ensure the livelihood of their businesses in this new country.

\section{CONCLUSION}

Leaders are promoters of change and challengers of the norm. They do and must encourage creativity and risk taking. Leaders concentrate on goals, objectives, mission, and vision. They are concerned with doing the ethical or right thing. A giver would be the best candidate to effectively carry out all these duties.

Corporations have grown into multinational firms due to trust, loyalty and support of the components they serve. Businesses are more global today. These firms are challenged with the task of maintaining trust and having to balance the many needs of their various stakeholders. Givers as leaders have the ability to heighten employee intelligence by allowing them to be motivated, creative, and innovative. They perceive interdependence as a source of strength. Givers as leaders have the ability to strap up the skills of multiple people for the greatest good of the firm. Collaborative efforts within firms are at their highest with givers. 
Technology has made many actions crystal clear as to what standards should be followed. Leaders today need to know how to be global leaders. This is a must in order for corporations to effectively function and succeed in the global market. Corporate social responsibility is an important element in carving out corporate image and livelihood. The global economy is real. Our world is interconnected. Corporations are somewhat aware, but need to be fully aware that CSR varies enormously from company to company and country to country. Many countries and corporations are underdeveloped in this area. Research has linked CSR to economic development. Companies making up the global economy may be forced to implement CSR. Company leaders must be aware of the dedication to CSR, and the CSR policies themselves within each country they are expanding to in order to better plan, improve and ensure the livelihood of their companies.

\section{AUTHOR INFORMATION}

Almerinda Forte, Ph.D., is an Associate Professor and Chairperson for the Division of Administration and Economics at St. John's University. She received her Ph.D. from New York University. Dr. Forte has presented papers at numerous business ethics conferences and international business conferences. She has published several articles in the Journal of Business Ethics, International Business and Economics Research Journal, Journal of Diversity Management, Journal of International Education Research and in Contemporary Issues in Business Ethics (2007) published Chapter 4 entitled "Business Ethics and the Corporate World." In addition to teaching, she was awarded a Senior Specialist Fulbright and has been appointed a Vincentian Research Fellow. Dr. Forte brings to the classroom her experience from numerous companies, including Merrill Lynch, Pierce, Fenner and Smith, and The New York State Society of CPA's. Dr. Almerinda Forte, Associate Professor and Chair, St. John's University, Division of Administration \& Economics, College of Professional Studies, 8000 Utopia Parkway, Queens, N.Y. 11439. E-mail: fortea@stjohn's.edu

\section{REFERENCES}

1. Alfareda L., Tencati A., Lozano J. M., \& Perini F. (2006). The government's role in promoting corporate responsibility: A comparative analysis of Italy and U.K. from the relational state perspective. Corporate Governance: The International Journal of Business in Society, 6(4), 386-400.

2. Baumeister R .F., Vohsk D., Aaker J. L., \& Garbinsky E. N. (forthcoming). Some key differences between a happy life and a meaningful life, Journal of Positive Psychology.

3. Dunn E. W., Akron B., \& Norton M. I. (2008). Spending money on others promotes happiness. Science, $319,1687-1688$.

4. Fiori, G., diDonato, F., \& Izzo, M. F. (2007). Corporate social responsibility and firms' performance: An analysis on Italian listed $\mathrm{n}$ companies. Luiss Guido Carli University, Italy. Luiss Guido Carlo, Luiss Homepage/Luiss Library page. Retrieved from http://eprints luiss.it/374/1/Fiori_2007_03_open.pdf or http://ssm.com/abstract=1032851 or email: fizzo@luiss.it.

5. Gates, B. (2008). Creative capitalism, world economic forum, January 24.

6. Grant, A. (2013). A revolutionary approach to success: Give and take. New York: Penguin Group.

7. Groysberg B., \& Lee L. E. (2008). The effect of colleague quality on top-performance: The case of security analysis. Journal of Organizational Behavior, 29, 1123-1144.

8. Groysberg B., Lee L. E., \& Nonda, A. (2008). Can they take it with them? The portability of star knowledge workers' performance. Management Science, 54, 1213-1230.

9. Hardy C .L., \& Vugt M. V. (2006). Nice guys finish first: The competitive altruism hypothesis. Personality and Social Psychology Bulletin, 32, 1402-1413.

10. Helgeson V. S., \& Fritz H. I. (2000). The implication of unmitigated agency and unmitigated communion for domains of problem behavior. Journal of Personality, 68, 1031-1057.

11. Hollander E. P. (1958). Conformity, status, and idiosyncrasy credit. Psychological Review, 65, 117-127.

12. Huckman R., \& Pisano G. (2006). The firm specificity of individual performance: Evidence from cardiac surgery. Management Science, 52, 473-488.

13. Kim E., \& Glomb T. (2010). Get smarty panty: Cognitive ability, personality, and victimization. Journal of Applied Psychology, 95, 889-901. 
14. Lambooy, T. (2010). Institutionalization of corporate social responsibility in the corporate governance code: the new trend of the Dutch model. In W. Sun, J. Stewart \& D. Pollard (Eds.) Critical studies on corporate responsibility, governance, and sustainability (vol. 1). Reframing corporate social responsibility: lessons from the global financial crisis (pp. 145-179). UK: Emerald Group Publishing Limited.

15. Lawrence, J. T. (Eds.) \& Beamish, P. W. (Eds.). (2013). Globally responsible leadership: Managing according to the UN global compact.

16. Maignan, I., \& Ralston, D. A. (2002). Corporate social responsibility in Europe and the U.S.: Insights from businesses' self-presentation. Journal of International Business Studies, 33, 497-514.

17. Perrini F., \& Tencati A. (2006). Sustainability and stakeholder management the needs for new corporate performance evaluation and reporting systems, Business Strategy and the Environment, 15(5), 296-308.

18. Uzzi B., \& Dunlap S. (2005). How to build your network. Harvard Business Review, December, 53-60.

19. Weinstein N., \& Ryan R. M. (2010). When helping helps: Autonomous motivation for prosocial behavior and its influence on well-being for the helper and recipient. Journal of Personality and Social Psychology, 98, 222-244.

20. Welford, R. (2004). Corporate social responsibility in Europe, North America, and Asia 2004 Survey results. JCC, Spring 2005, Copyrighted 2005 by Greenleaf Publishing. 